Investigations

\title{
Simulation and Experimental Analysis of a Demonstrative Solar Heating and Cooling Plant Installed in Naples (Italy)
}

\author{
Annamaria Buonomano, Francesco Calise, \\ Massimo Dentice d'Accadia, Raffaele Vanoli and Maria Vicidomini \\ DII, Department of Industrial Engineering, University of Naples Federico II, P.le Tecchio 80, 80125 Naples, Italy
}

\author{
Article history \\ Received: 03-08-2016 \\ Revised: 21-09-2016 \\ Accepted: 21-09-2016 \\ Corresponding Author: \\ Francesco Calise \\ DII Department of Industrial \\ Engineering, University of \\ Naples Federico II, P.le \\ Tecchio 80, 80125 Naples, Italy \\ Email: frcalise@unina.it
}

\begin{abstract}
In this study the model of a Solar Heating and Cooling (SHC) system and its experimental setup are presented. The SHC system under investigation is a demonstration plant installed in Naples, based on flat plate solar collectors and a single-stage $\mathrm{LiBr}-\mathrm{H}_{2} \mathrm{O}$ absorption chiller. In addition, two vertical tanks are installed as storage system. The balance of system includes: A cooling tower, pumps, valves, safety devices and pipes. The absorption chiller is powered only by solar energy, since there are devices for auxiliary thermal energy. The experimental setup also includes a number of meters (temperature, pressure, flow rate and radiation) to measure, collect and control the prototypal system. The experimental plant is dynamically designed and simulated in order to calculate its energetic and economic performance parameters. This analysis is carried out by means of a zero-dimensional transient simulation model, developed by using the TRNSYS software. Furthermore, a parametric analysis is implemented, aiming at determining the set of the synthesis/design variables that maximize system performances. The model was validated by the first experimental results obtained by the operation of the solar cooling system. Results show that, although flat-plate solar collectors have been specially designed for this kind of application, their operating temperature is often too low to drive the absorption chiller. In addition, the system performance is not particularly sensitive to the storage volume whereas the thermal capacity of the solar field is lower than the absorption chiller demand, determining a very discontinuous operation of the chiller itself.
\end{abstract}

Keywords: Solar Cooling, TRNSYS, Simulation, Experimental Setup, Energy, Sustainability

\section{Introduction}

Solar Heating and Cooling (SHC) is one of the most promising renewable technologies. A SHC system exploits solar irradiation, incident on a solar collector field, for the combined production of both heating and cooling energies. Thus, the SHC technology is particularly attractive for its summer operation mode, i.e., when the cooling energy demand is often simultaneous with the availability of solar radiation (Buonomano et al., 2014; Kalogirou, 2014).

Although the high recent interest of researchers and organizations in the SHC technology growth, the International Energy Agency (IEA) promoted the use of such renewable energy technology in the late 1977 by leading the Solar Heating and Cooling Program development (IEA, 2011). However, solar heating and cooling systems are still at the margin of the market, mostly due to the very high installation cost and to the lack of system knowledge by designers and installers. For this purpose, experimental analyses (Wang et al., 2008; Hang et al., 2014; Yu et al., 2014), advanced modelling and simulation tools (Calise et al., 2010a; $2010 \mathrm{~b}$ ) of SHC plants play an important role for analysing and optimizing (Vargas et al., 2009; Calise et al., 2011; Hang et al., 2013) the system layout, the control strategy (Mosallat et al., 2013; Grynning et al., 2014) and the components operation.

As an example, analyses and optimizations were performed by (Assilzadeh et al., 2005; Ghaddar et al., 1997) for a Malaysian building and for a solar cooling prototype located in Beirut, respectively. Atamaca and Abdulvahap (2003) performed a similar study for the 
city of Antalya (Turkey) by implementing a more complex mathematical model for $\mathrm{LiBr}-\mathrm{H}_{2} \mathrm{O}$ Absorption Chiller. An interesting economic and energetic analysis for different types of building located in several European climates was presented by (Mateus and Oliveira, 2009). Here, authors investigated a SHC system capable to provide space cooling and heating and Domestic Hot Water (DHW), according to the user demand. Such study was based on a simulation model developed in TRNSYS, whose results showed that a competitive SHC operation can be obtained only for the EU southern regions. An experimental work was performed by (Hammad and Zurigat, 1997) for a Jordan building. Here, authors described the performance of a 1.5-ton solar cooling prototype, focusing on to the variation of the Coefficient of Performance (COP) of the Absorption CHiller ( $\mathrm{ACH})$, as a function of the solar irradiance.

Some of the papers available in literature also investigated the systems from the economic point of view: For example, (Mateus and Oliveira, 2009) determined the optimal set of design and operating parameters of a SHC system by using dynamic simulations. Similarly, Hang et al. (2013) presented a multi-objective optimization for SHC systems providing space heating and cooling to medium-sized office buildings. Their approach is based on the Central Composite Design (CCD) and it allows one to define the optimal design parameters of the SHC system as a function of building typology and climate.

SHC systems were also analyzed by using the Life Cycle Analysis (LCA) technique: In this framework (Beccali et al., 2012) showed that for SHC systems located in Italy and in Switzerland the energy and $\mathrm{CO}_{2}$ emission payback times as well as the energy return ratio range from 4 to 6 years. Exergy and life cycle analyses were also performed by (Koroneos and Tsarouhis, 2012) for a solar system, for space heating, cooling and hot domestic water production, applied to a residence located in Greece. Results show that the solar cooling system, compared to solar heating, hot water and photovoltaic systems, has the highest overall environmental impact, mostly due to its devices manufacturing.

The definition of a common procedure to measure the SHC system performance was developed by (Nowag et al., 2012). Here, in order to compare different systems and provide a good overview of the performances of a SHC installation, a procedure on the determination of SHC system performance indicators was presented. Finally, many authors have been involved in investigations and optimizations of some innovative SHC system configurations including: Heat pumps for summer and/or winter auxiliary energy (Calise, 2010; Calise et al., 2012) and different thermal storage strategy (Buonomano et al., 2013). Recently, SHC systems applied to residential buildings have been widely investigated.

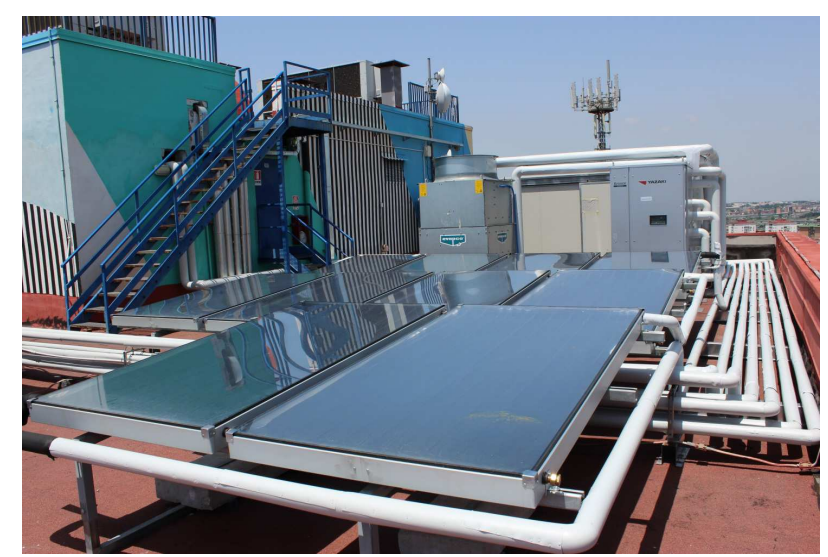

Fig. 1. A view of the SHC plant installed on the $\mathrm{ABC}$ headquarter roof

In particular, in order to achieve a near zero energy building, a high fraction of renewable energies has to be employed. From this point of view, possible methods for covering part of the demand for heating, cooling and domestic hot water by using solar technologies are discussed by several authors (Baldwin and Cruickshank, 2012; Henning and Döll, 2012).

As shown before, a number of papers are available in literature presenting numerical analyses of solar heating and cooling system. Conversely, experimental analyses of such systems are relatively scarce compared with those based on numerical simulations.

This study combines both numerical and experimental analyses. First, the model of a prototype of solar heating and cooling is presented. Then, the experimental setup, including mechanical devices and meters, is analysed. Finally, the first gathered experimental data are presented and compared with numerical results. In particular, this paper is focused on the description of the experimental set up of a prototypal solar cooling system installed on the roof of the headquarters of the public water company "ABC of Naples" located in Naples (Italy), shown in Fig. 1. The installation was completed in September 2014 and the first experimental data were collected and analysed. These data are used to validate the SHC system modelled and simulated in TRNSYS platform.

\section{Experimental Set-Up}

The layout of the proposed Solar Heating and Cooling (SHC) system is schematically shown in Fig. 2. Other system configurations have been investigated by the authors, e.g., in references (Calise et al., 2011; 2012). The system includes:

- Four Solar Collector fields, SC, consisting of flat plate collectors, FPC, heating the Solar Collector Fluid (SCW) 
- A $\mathrm{LiBr}_{-} \mathrm{H}_{2} \mathrm{O}$ single-effect Absorption CHiller $(\mathrm{ACH})$, whose generator is fed by the Hot Water (HW), heated up by the solar field; the condenser and the absorber of the $\mathrm{ACH}$ are cooled by the Cooling Water loop (CW) provided by the closedcircuit Cooling Tower (CT); the evaporator supplies CHilled Water (CHW) for space cooling demands

- A fixed-volume Pump (P1) for the HF loop; four variable-speed Pumps for the SCW loop; a fixedvolume Pump (P3) for the CW loop; a fixed-volume Pump (P4) for the CHW loop; a fixed volume Pump (P2) for the flow between HE3 and Tank (TK) in SCW loop

- A plate-fin Heat Exchanger (HE3) in the SCW loop, transferring the heat from the SC to the Tank

- Two plate-fin Heat Exchanger (HE1 and HE2) in the HW and CHW loops, used to supply heating energy demand (HE1) or cooling energy demand (HE2)

- Pipes, mixers, diverters, valves and controllers required for the system operations

In the following, the main elements of the experimental set up are described in details. The main design parameters are reported in Table 1. In Fig. 3 the whole system plant is shown.

\section{Solar Field}

The installed solar field is based on selective flat plate collectors, manufactured and tested by Idaltermo (Acquarica del capo-Lecce-Italy) (Fig. 4). Collector sizes are $2.15 \times 1.15 \mathrm{~m}$, for an area of $2.47 \mathrm{~m}^{2}$. The prototype is equipped with a high selectivity absorber (95 and 5\% absorption and emissivity factors, respectively). The panel is assembled on site. The collector includes the following components:
- A clear glass cover

- A $10 \mathrm{~mm}$ copper tube

- Rock wool insulation

- An aluminum case

The solar field layout has been designed considering both possible shadowing and structural constrains. The layout has been chosen taking into account all the shadows cast by the construction located on the middle of the roof (dashed in Fig. 3), 3 $\mathrm{m}$ height and also by part of perimeter walls, $1.5 \mathrm{~m}$ height. The central construction is never shaded during the day and it could have been a proper site to install the collectors. However, this site is occupied by two heat pumps and no change at their layouts was permitted. These conditions limit the available surface area for the installation of the solar field.

The entire solar field consists of 4 arrays connected in parallel. Two arrays include 7 collectors and the other two have 8 and 10 collectors respectively; for a total number of 32 collectors occupying an area of $79 \mathrm{~m}^{2}$. All panels are tilt at an angle of $5^{\circ}$ from the horizontal and are placed at 77 $\mathrm{cm}$ above the roof top level. It is worth noting that this tilt angle is much lower than the optimal one for Naples (around 34). This is due to the available roof area for collector installation, which is small with respect to the demanded capacity. In fact, a higher collector tilt angle would determine self-shading issues, determining a consequent reduction of the available area for the solar collector field. As a consequence, in order to maximize the solar field capacity, a near-horizontal layout was selected. The small angle of $5^{\circ}$ is required in order to prevent air formation inside the collector pipes and dust deposition on the covering glass.

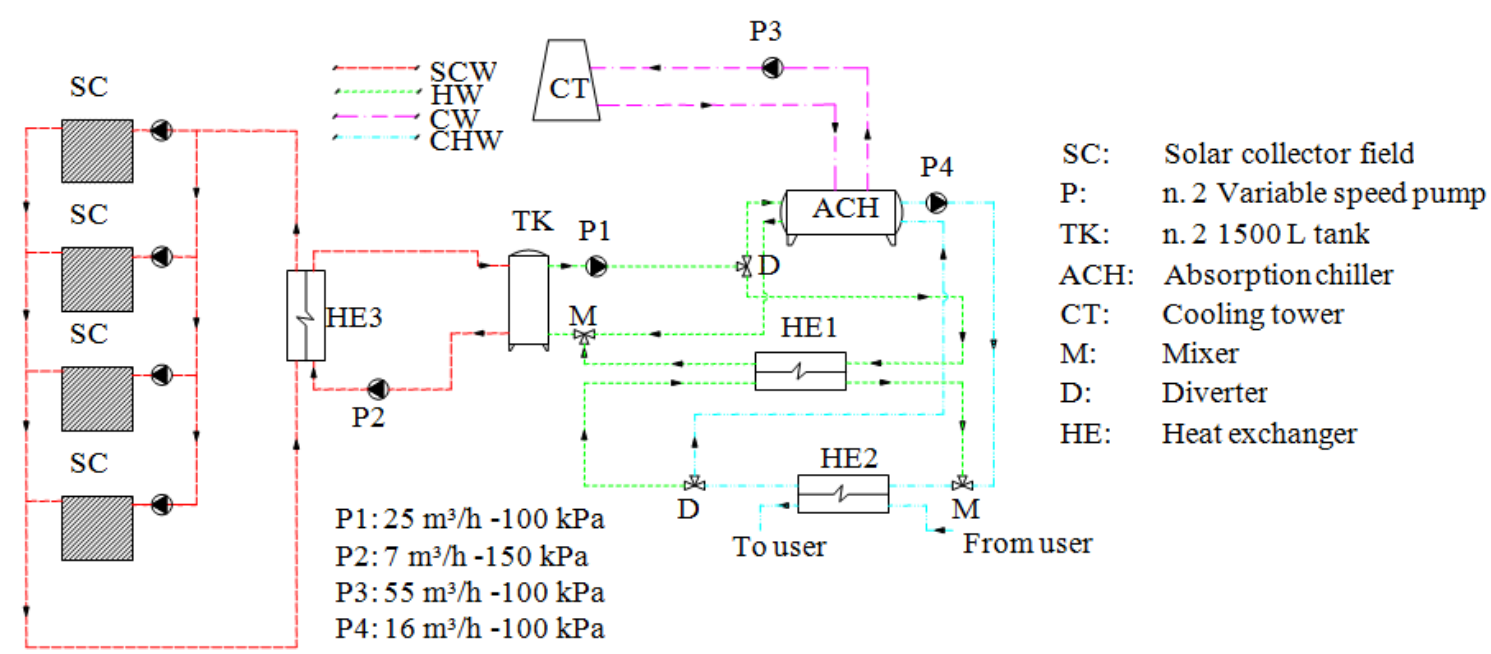

Fig. 2. System layout 


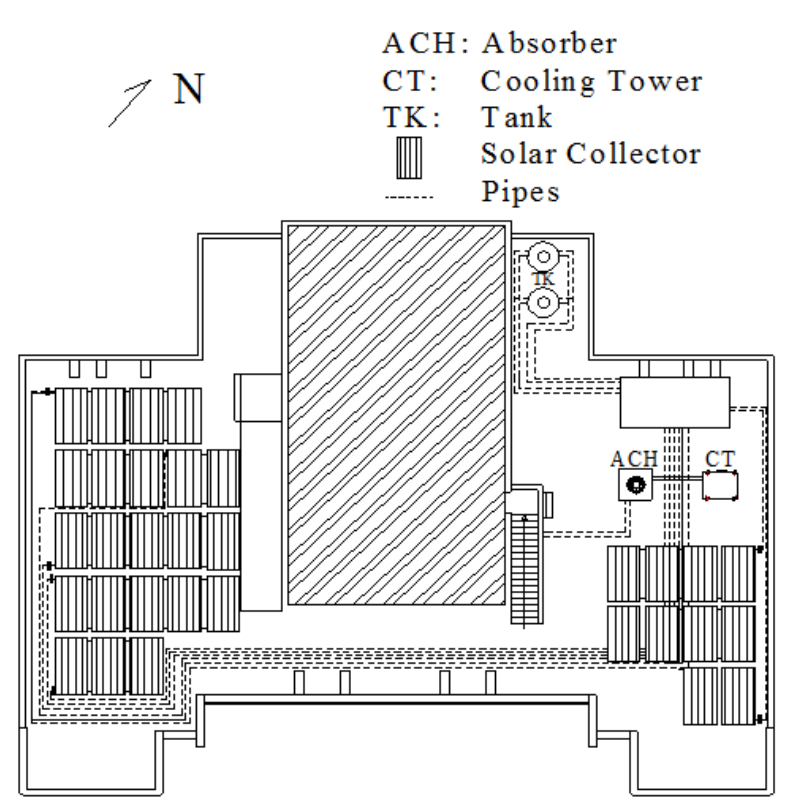

Fig. 3. System plant

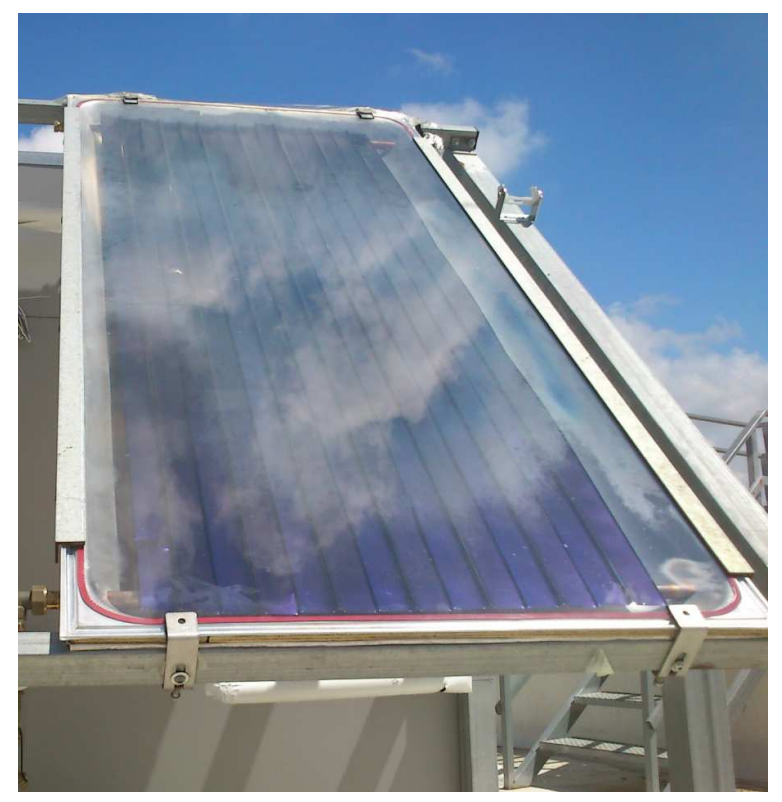

Fig. 4. Prototype of installed solar collector

\section{Storage}

In a SHC system, the adoption of a proper strategy for the thermal energy storage is crucial. SHC system performances highly depend on the simultaneity between the solar availability and the heating and cooling demands (Buonomano et al., 2013). A mismatch between the supply and the demand often occurs during the system operation. Thus, in order to limit such mismatch and to balance the energy requirements, it is necessary to exploit as much as possible the solar energy.
Table 1. Design parameters

\begin{tabular}{lll}
\hline Description & Value & Unit \\
\hline Number of FPC & 32 & Collectors \\
Collectors Area & 79 & $\mathrm{~m}^{2}$ \\
ACH rated chilled power & 70.3 & $\mathrm{~kW}$ \\
ACH rated hot power & 100 & $\mathrm{~kW}$ \\
SC pump flow/SC Area & 100 & $\mathrm{~kg} / \mathrm{h} \mathrm{m}^{2}$ \\
P1 flow & 25 & $\mathrm{~m}^{3} / \mathrm{h}$ \\
P2 flow & 7 & $\mathrm{~m}^{3} / \mathrm{h}$ \\
P3 flow & 55 & $\mathrm{~m}^{3} / \mathrm{h}$ \\
P4 flow & 16 & $\mathrm{~m}^{3} / \mathrm{h}$ \\
Tank volume & 1500 & 1 \\
CT electrical rated fan power & 2.2 & $\mathrm{~kW}$ \\
CT thermal rated power & 256 & $\mathrm{~kW}$ \\
CT design air flow rate & 22680 & $\mathrm{~m}^{3} / \mathrm{h}$ \\
SC outlet set point temperature & 90 & ${ }^{\circ} \mathrm{C}$ \\
ACH inlet set point temperature & 85 & ${ }^{\circ} \mathrm{C}$ \\
ACH set point chilled temperature & 7 & ${ }^{\circ} \mathrm{C}$ \\
Minimum tank temperature HW & & \\
circuit activation (summer) & 85 & ${ }^{\circ} \mathrm{C}$ \\
Minimum tank temperature HW & & \\
circuit activation (winter) & 55 & ${ }^{\circ} \mathrm{C}$ \\
\hline
\end{tabular}

For this application a storage system composed by two tanks is designed and installed. One of the aims of the experimental and numerical analyses here presented is to find the optimal storage strategy concerning the use of one or two tanks connected in series. Figure 5 shows the layout of the adopted storage system. Note that the capacity of each tank is of 15001 .

In order to enable different system operations, three storage management strategies, depending on the position of valves, are implemented. They can be summarized as:

- The solar field charges, through the heat exchanger, the top of Tank 1. Hot water is pumped from the top of Tank 1 and supplied to the absorption chiller. Cold water always returns to the bottom of Tank 1 and, then, it returns to the solar field to be heated

- The solar field charges the top of Tank 1. Hot water is brought from the top of Tank 1 and supplied to the absorption chiller. Cold water returns to the bottom of the Tank 2. The top of Tank 2 is charged by the bottom of Tank 1 . Cold water always returns to the solar field from the bottom of Tank 2

- The tanks are not connected. A direct feeding from the solar field to the absorption chiller is performed

\section{Absorption Chiller}

The installed chiller is a $\mathrm{LiBr}-\mathrm{H}_{2} \mathrm{O}$ single-effect Absorption Chiller (ACH). The device is manufactured by Yazaki. The type is WFC-SC 20, with chilled power of $70.3 \mathrm{~kW}$. The rated output chilled water temperature is $7^{\circ} \mathrm{C}$, returning back at $12.5^{\circ} \mathrm{C}$. The rejecting thermal power is $170.8 \mathrm{~kW}$ with a rated output temperature of 
$35^{\circ} \mathrm{C}$ that returns at $31^{\circ} \mathrm{C}$. For this reason a counter current cooling tower equipped with axial fans is installed. Note that the rated data of the absorption chiller are referred to the hot water inlet temperature of $88^{\circ} \mathrm{C}$, being the chiller able to operate with inlet hot water temperatures higher than $70^{\circ} \mathrm{C}$. However, a temperature of $88^{\circ} \mathrm{C}$ is not easy to achieve by flat plate (non-evacuated) solar collectors. Therefore, the actual cooling capacity of the absorption chiller is expected to be around $30 \mathrm{~kW}$ when the operating temperature of the solar field is around $75-80^{\circ} \mathrm{C}$.

\section{Monitoring and Control}

In order to monitor the SHC system, a special experimental set up has been designed and installed. Flow meters, temperature probes and a pyranometer have been installed. The system control includes motorized three-way valves and inverter engines installed on the pumps. A layout showing the meters and their location is provided in Fig. 6. Each input signals is collected by a datalogger which is also able to provide the output signals required to manage the equipment (3way valves, pumps, inverters, cooling tower and absorption chiller activation, etc.). The position of sensors has been defined in order to measure entering and leaving fluxes and temperature of the fluid in any significant node of the system. In the following, mass flow, temperature and pressure probes, pyranometer and datalogger are described.

\section{Mass Flow}

In this project two types of mass flow meters have been selected: Electromagnetic flow meters for HW, $\mathrm{CW}, \mathrm{CHW}$ and SCW (from TK to HE3), whereas vortex flow meters for other parts of SCW with the aim of measuring the flows of each solar field.

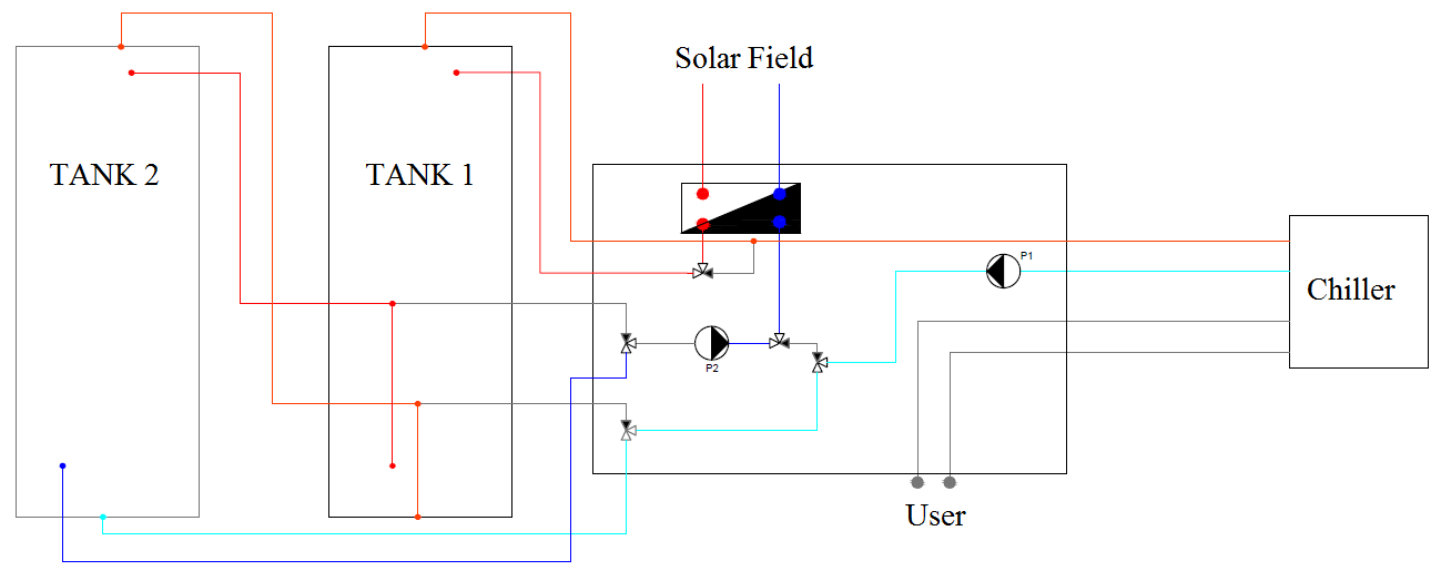

Fig. 5. Storage system layout (2 Tank activated)

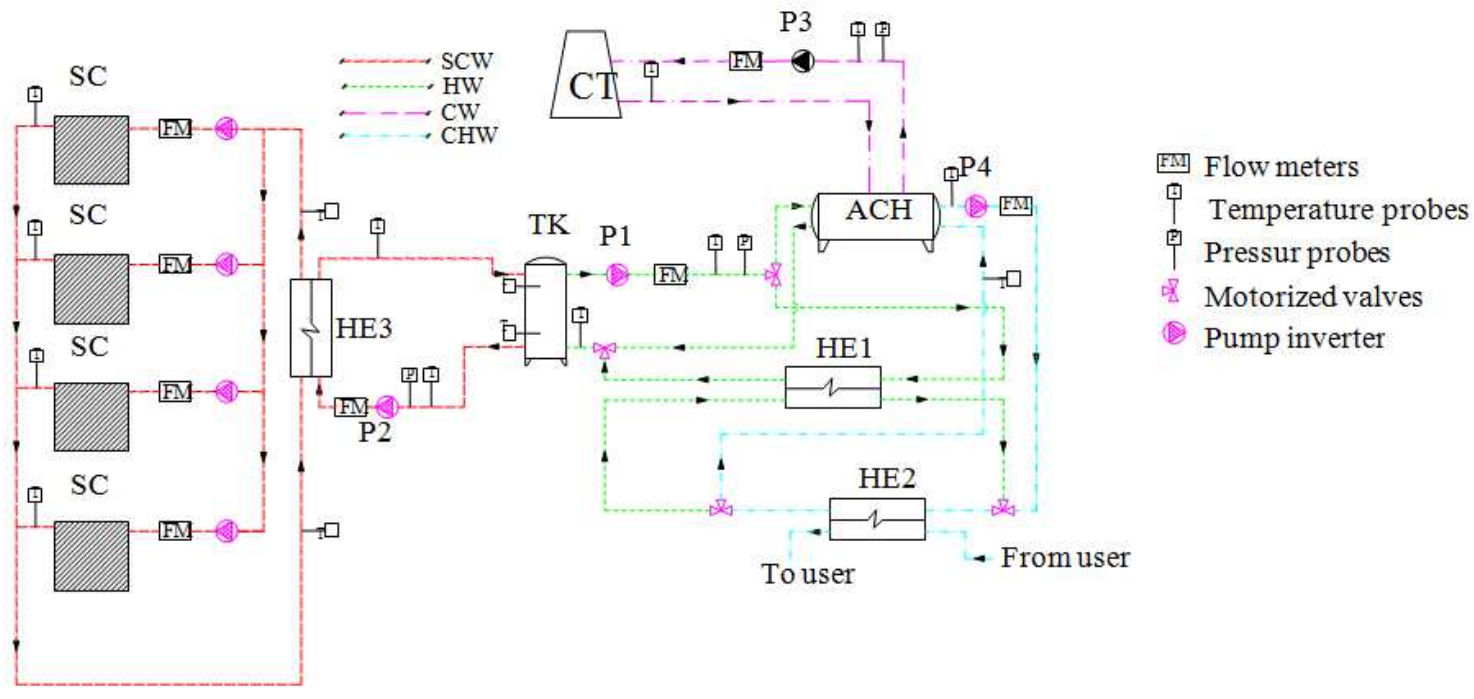

Fig. 6. Monitoring and control setup 
The electromagnetic flow meter includes two sections. A primary element generates the measurement signal and a secondary element (also named converter) processes and delivers the signal to the data logger. The flow measurement is based on induction Faraday's law, where an induced voltage is generated when a conductive fluid flows through a magnetic field. This technology shows several advantages compared with other available ones, such as: Reliable flow measurement for conductive fluid $>5 \mu \mathrm{S} / \mathrm{cm}$; maintenance free; no moving part and straight through flow tube (no pressure loss); tolerant to aggressive or hot fluids. In this project M-Series ${ }^{\circledR}$ Electromagnetic Flow Meters by Badger Meter is used (Fig. 7). These components features are:

- $\quad$ Accuracy of $\pm 0.5 \%$

- Sizes: DN 50

- Power supply: $240 \mathrm{Vca}$

- Output: $4 . .20 \mathrm{~mA}$

- Min-max flow: 59-1414 1/min

The vortex flow meter involves placing a shedder bar in the path of the fluid. As the fluid passes this bar, disturbances in the flow called vortices are created. The vortices trail behind the cylinder, alternatively from each side of the bluff body. The frequency at which these vortices alternate sides is essentially proportional to the flow rate of the fluid. The used flow meter is the Vortex Flow sensor by Grundfos (Fig. 8), having the following features:

- Accuracy of $\pm 1.5 \%$

- $\quad$ Sizes: DN 20

- Power supply: 5 Vcc

- Output: 0.5 to $3.5 \mathrm{~V}$

- Min-max flow: 2-40 1/min

\section{Temperature Probes}

In this project two type of probes are installed, namely: A class A platinum Resistance Temperature Detector (RTDs) with the signal converter in its terminal head (Fig. 9a) for HW, CW, CHW and SCW (from TK to HE3); a class B RTD with an external converter (Fig. 9b) for other part SCW in order to measure the flows of each solar field. This difference depends on diameter tube and spacing inside the box. Both probes have a three-wire configuration, in order to minimize the effects of the lead resistances. By using this method, the two leads to the sensor are on adjoining arms. There is a lead resistance in each arm of the bridge so that the resistance is cancelled out, so long as the two lead resistances are accurately the same. The accuracy are \pm 0.40 and $\pm 0.15^{\circ} \mathrm{C}$ for class $\mathrm{B}$ and class A respectively (at $20^{\circ} \mathrm{C}$ ). The output signal after the converter is both 4-20 mA.

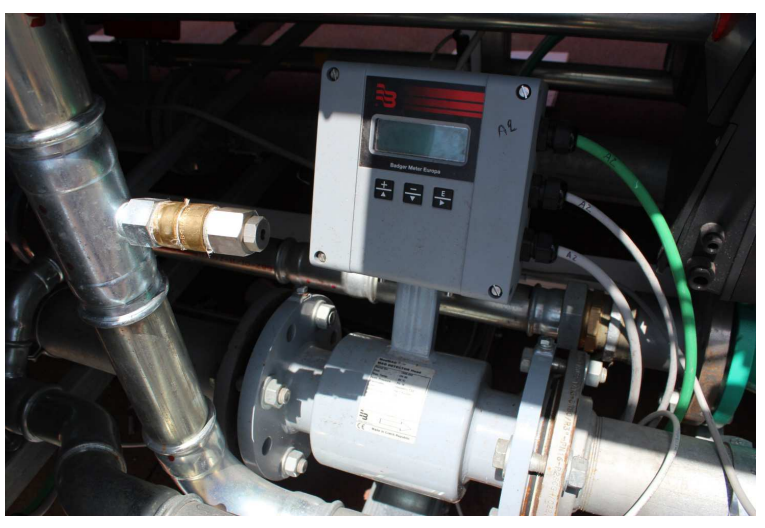

Fig. 7. Installed electromagnetic mass flow meter

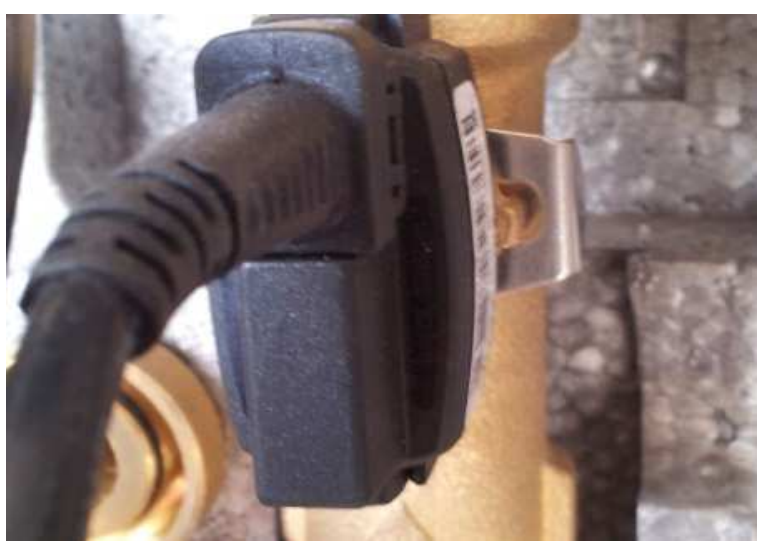

Fig. 8. Installed vortex flow meter
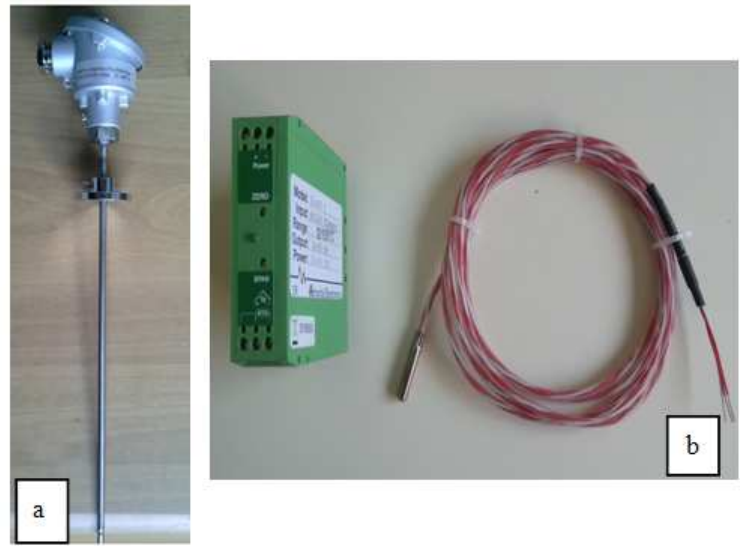

Fig. 9. Installed temperature probes

\section{Pyranometer}

In order to measure the global solar radiation, a pyranometer is installed. In order to attain the proper directional and spectral characteristics, the main components of the pyranometer are: A thermopile sensor with a black coating and a glass dome. The thermopile sensor absorbs all solar radiation, has a flat spectrum covering the 300 to 50,000 nanometer range and has a near-perfect cosine response. 


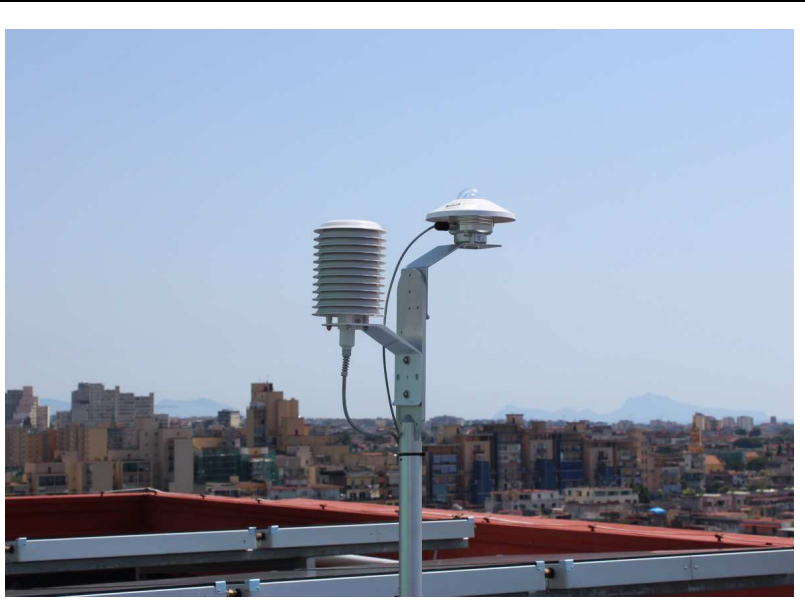

Fig. 10. Installed Pyranometer LP PYRA 02

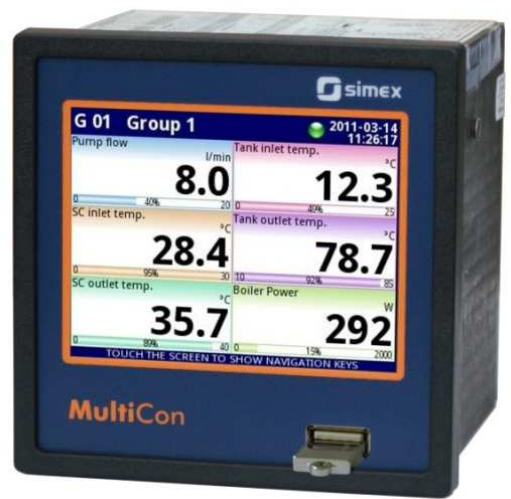

Fig. 11. Datalogger multicon CMC 141

Meanwhile, the glass dome limits the spectral response from 300 to 2,800 nanometers (cutting off the part above $2,800 \mathrm{~nm}$ ), while preserving the 180 degrees field of view. Another function of the dome is that it shields the thermopile sensor from convection.

The black coating on the thermopile sensor absorbs the solar radiation. This radiation is converted to heat. The heat flows through the sensor to the pyranometer housing. Then, the thermopile sensor generates a voltage output signal that is proportional to the solar radiation.

The selected pyranometer is the LP PYRA 02 AC manufactured by DELTA OHM (Fig. 10). It is a First Class Pyranometer according to ISO 9060, 4-20 mA signal Output; measurement range $<2000 \mathrm{Wm}^{-2}$.

\section{Datalogger}

Any output and input signal is managed by a datalogger. The selected technology is the Multicon CMC-141 by Simex (Fig. 11). The MultiCon CMC 141 is multichannel unit which enables simultaneous measurements, visualisations and controls of different signals.
Table 2. Channel configuration

\begin{tabular}{|c|c|c|}
\hline Input/Output & Channel name & Measure \\
\hline \multicolumn{3}{|l|}{ CMC 141} \\
\hline Input 1-Module B & In SL1 & T In Solar Loop 1 \\
\hline Input 2-Module B & Out SL1 & T Out Solar Loop 1 \\
\hline Input 3-Module B & In SL2 & T In Solar Loop 2 \\
\hline Input 4-Module B & Out SL2 & T Out Solar Loop 2 \\
\hline Input 5-Module B & In SL3 & T In Solar Loop 3 \\
\hline Input 6-Module B & OutSL3 & T Out Solar Loop 3 \\
\hline Input 7-Module B & In SL4 & T In Solar Loop 4 \\
\hline Input 8-Module B & Out SL4 & T Out Solar Loop 4 \\
\hline Input 9-Module B & S9 & T Tank 1 Bottom \\
\hline Input 10 -Module $\mathrm{B}$ & S8 & T Tank 1 Middle \\
\hline Input 11-Module B & S7 & T Tank 1 Top \\
\hline Input 12-Module B & $\mathrm{S} 11$ & T Tank 2 Bottom \\
\hline Input 13-Module B & S10 & T Tank 2 Top \\
\hline Input 14-Module B & $\mathrm{S} 2$ & T HE2 In \\
\hline Input 15-Module B & $\mathrm{S} 1$ & T HE2 Out \\
\hline Input 16-Module B & $\mathrm{S} 12$ & T Chiller In \\
\hline Input 17-Module B & $\mathrm{S} 13$ & T Chiller Out \\
\hline Input 18-Module B & S6 & T Tower In \\
\hline Input 19-Module B & $\mathrm{S} 4$ & $\mathrm{~T}$ Tower Out \\
\hline Input 20-Module B & S5 & T supply \\
\hline Input 21-Module B & $\mathrm{S} 3$ & T return \\
\hline Input 22-Module B & Pyr & Solar Radiation \\
\hline Input 1-Module A & A3 & P2 flow meter \\
\hline Input 2-Module A & A4 & P1 flow meter \\
\hline Input 3-Module A & A1 & P3 flow meter \\
\hline Input 4-Module A & $\mathrm{A} 2$ & P4 flow meter \\
\hline Output1-Module C & Inverter P1 & Inverter P1 \\
\hline Output2-Module C & Inverter P2 & Inverter P2 \\
\hline Output3-Module C & Inverter P4 & Inverter P4 \\
\hline \multicolumn{3}{|l|}{ Module SIN-8 } \\
\hline Input1 & Yazaki & Chiller status \\
\hline Input2 & VD1 & VD1 valve status \\
\hline Input3 & VD2 & VD2 valve status \\
\hline Input4 & VD3 & VD3 valve status \\
\hline Input5 & VD4 & VD4 valve status \\
\hline Input6 & VD5 & VD5 valve status \\
\hline Input7 & VD6 & VD6 valve status \\
\hline Input8 & VD7 & VD7 valve status \\
\hline \multicolumn{3}{|l|}{ Module SIAi-8P } \\
\hline Input1 & L1 & Solar Loop 1 flow meter \\
\hline Input2 & L2 & Solar Loop 2 flow meter \\
\hline Input3 & L3 & Solar Loop 3 flow meter \\
\hline Input4 & L4 & Solar Loop 4 flow meter \\
\hline \multicolumn{3}{|l|}{ Module SO8 } \\
\hline Output1 & Yazaki & Chiller on/off control \\
\hline Output2 & VD1 & VD1 control \\
\hline Output3 & VD2 & VD2 control \\
\hline Output4 & VD3 & VD3 control \\
\hline Output5 & VD4 & VD4 control \\
\hline Output6 & VD5 & VD5 control \\
\hline Output7 & VD6 & VD6 control \\
\hline Output8 & VD7 & VD7 control \\
\hline
\end{tabular}

The datalogger displays all data and dialogue on a TFT screen. Full control of the device is obtained through the built-in touch-panel. The datalogger is configured with three modules: 


\section{Module (A)}

$4 \times$ analogue flowmeter input $+4 \times$ current input

- Measurement range

- Flow input modes: $0 \div 20,4 \div 20 \mathrm{~mA}$

- Flow input units: $1 / \mathrm{sec}, 1 / \mathrm{min}, 1 / \mathrm{h}$

- Current input: $0 \div 20,4 \div 20 \mathrm{~mA}$

Module (B)

$24 \times$ current input:

- Measurement range

- $0 \div 20,4 \div 20 \mathrm{~mA}$

Module (C)

$8 \times$ current output:

- Nominal analogue range:

- $4 \div 20 \mathrm{~mA}$

Other three modules are connected via modbus to the main datalogger:

- $\quad$ SIN-8: Collecting 8 digital voltage input

- SIA-8P: Collecting 8 analogic or digital current or voltage input

- $\quad$ SOC-8: Collected 8 digital output

Each module is developed by Simex. All the configured channels are shown in Table 2.

\section{Simulation Model}

In order to simulate the proposed SHC system layouts, the dynamic simulation software TRNSYS is used. The TRNSYS software includes a large library of built-in components, often validated by experimental data (Klein, 2006). As above mentioned, the simulated SHC system was originated from the experimental setup layout. Therefore, in this section only a brief description of some of the main components of the system is provided. In fact, the overall model includes a number of additional sub-models (controllers, pumps, valves, mixers, pipes, weather data, etc.). However, the reader may refer to the papers available in literature for further details regarding those components (Klein, 2006; Calise, 2010; Calise et al., 2010a; 2010b; Calise et al., 2011; Calise, 2012; Calise et al., 2012; Buonomano et al., 2013; 2014).

\section{Solar Collector}

To simulate the solar Flat Plate Collectors (FPC) behaviour, the built-in TRNSYS Type 1 is used. Here, to models a FPC a quadratic efficiency curve is implemented. This model assumes that the FPC efficiency vs. $\Delta T / I_{T}$ curve can be modelled as a quadratic equation (where $I_{T}$ is global radiation incident on the solar collector). The general equation for collectors efficiency is obtained from Hottel-Whillier equation, given by:

$$
\eta=\frac{\dot{Q}_{u}}{S I_{T}}=\frac{\dot{m} c_{p, f}\left(T_{\text {out }}-T_{\text {in }}\right)}{S I_{T}}=F_{R}(\tau \alpha)_{n}-F_{R} U_{L} \frac{\left(T_{\text {in }}-T_{a}\right)}{I_{T}}
$$

The loss coefficient $U_{L}$ is not constant, it depends on the inlet and ambient temperature difference. A better expression of is:

$$
\begin{aligned}
& \eta=\frac{\dot{Q}_{u}}{S I_{T}}=\frac{\dot{m} c_{p, f}\left(T_{\text {out }}-T_{\text {in }}\right)}{S I_{T}}=F_{R}(\tau \alpha)_{n}+ \\
& -F_{R} U_{L} \frac{\left(T_{i n}-T_{a}\right)}{I_{T}}-F_{R} U_{L / T} \frac{\left(T_{i n}-T_{a}\right)^{2}}{I_{T}} \\
& \eta=a_{0}-a_{1} \frac{\left(T_{i n}-T_{a}\right)}{I_{T}}-a_{2} \frac{\left(T_{i n}-T_{a}\right)^{2}}{I_{T}}
\end{aligned}
$$

The equation defines the dependency of the thermal efficiency by 3 parameters: $a_{0}, a_{1}$ and $a_{2}$. Those parameters are available for all collectors tested according to ASHRAE standards (Beccali et al., 2012) as well as for collectors tested according to European Standards on solar collectors (Koroneos and Tsarouhis, 2012). Laboratory tests by Idaltermo provide corrections coefficients values.

Tank

The tanks are modelled by using the TRNSYS builtin Type 4. The model is based on the assumption that a tank can be divided into $\mathrm{N}$ fully-mixed equal subvolumes. The tanks are also equipped with a pressure relief valve, in order to account the boiling effects. The model takes into account the energy released by the fluid flowing through the valve, whereas the corresponding loss of mass is neglected. The temperatures of the $\mathrm{N}$ nodes are calculated on the basis of unsteady energy and mass balances. The energy balance on the i-th tank layer can be written as follows:

$$
\begin{aligned}
& M_{i} c_{p, f} \frac{d T_{i}}{d \vartheta}=\alpha_{i} \dot{m}_{H} c_{p, f}\left(T_{H}-T_{i}\right)+ \\
& \quad+\beta_{i} \dot{m}_{L} c_{p, f}\left(T_{L}-T_{i}\right)+U A_{i}\left(T_{a}-T_{i}\right)
\end{aligned}
$$

To equation it has to be summed:

$$
\begin{aligned}
& +\gamma_{i} c_{p}\left(t_{i-1}-t_{i}\right) \text { if } \gamma_{i}>0 \\
& +\gamma_{i} c_{p}\left(t_{i}-t_{i+1}\right) \text { if } \gamma_{i}<0
\end{aligned}
$$

The coefficient $\alpha_{i}$ is equal to 1 if the $\mathrm{i}$-th segment corresponds to the top of the tank, otherwise is 0 , Similarly, $\beta_{i}$ is equal to 1 if the $\mathrm{i}$-th segment corresponds to the bottom of the tank, otherwise is 0 . The control function $\gamma_{i}$ is in this case defined as follows:

$\gamma_{i}=\dot{m}_{H} \sum_{j=1}^{i-1} \alpha_{j}-\dot{m}_{L} \sum_{j=i+1}^{N} \beta_{j}$ 


\section{Absorption Chiller}

A single-effect hot water $\mathrm{LiBr}-\mathrm{H}_{2} \mathrm{O}$ absorption chiller was considered. The component is simulated by using a normalized catalogue data lookup approach. TRNSYS Type 107 is used. It reads the cooling machine performance data from a data file which provides results as a function of the following four parameters: Fraction of design load; chilled water setpoint temperature; entering chilled water temperature; inlet hot water temperature. All these data are provided by the manufacturer. The ACH nominal capacity is calculated as:

$$
\dot{Q}_{c o o l, A C H, \text { rated }}=f_{A C H} \dot{m}_{P 4} c_{p, f} \Delta t_{C H W, n}
$$

The performance data are numerically expressed by the cooling ratio factor and the input heat ratio factor, as shown in following equations:

$$
\begin{gathered}
f_{Q_{C}}=\frac{\dot{Q}_{\text {cool }, A C H}}{\dot{Q}_{\text {cool }, A C H, \text { rated }}}=\vartheta\left(f_{D L}, T_{i n, C H W}, T_{i n, H W}, T_{i n, C W}, T_{\text {set }, \text { out }, C H W}\right) \\
f_{Q_{H}}=\frac{\dot{Q}_{H, A C H}}{\dot{Q}_{H, A C H, \text { rated }}}=\vartheta\left(f_{D L}, T_{i n, C H W}, T_{i n, H W}, T_{i n, C W}, T_{\text {set }, \text { out }, C H W}\right)
\end{gathered}
$$

Note that the rated input hot water flow rate $Q_{H, A C H, \text { rated }}$ is determined in relation to a fixed value of the coefficient of performance of the ACH:

$$
\dot{Q}_{H, A C H, \text { rated }}=\frac{\dot{Q}_{\text {cool }, \text { ACH, rated }}}{C O P_{A C H, \text { rated }}}
$$

The thermal rate required to cool the $\mathrm{ACH}$ is:

$$
\dot{Q}_{A C H, c o o l, r e q}=\dot{m}_{C H W} c_{p, f, C H W}\left(T_{i n, C H W}-T_{s e t, C H W}\right)
$$

Therefore, the design load ratio is:

$$
f_{D L}=\frac{\dot{Q}_{A C H, \text { cool }, \text { req }}}{\dot{Q}_{A C H, \text { cool, rated }}}
$$

Hence, by the factors defined in Equations and, the cooling and heating rates at any given time can be computed. Such values are subsequently employed in the energy balances, aiming to calculate the outlet temperatures of hot water, cooling water and chilled water. The device $\mathrm{COP}$ can be calculated by means of Equation:

$$
\begin{aligned}
& \dot{Q}_{C H W}=\dot{Q}_{C W}+\dot{Q}_{H W} \\
& T_{C H W, \text { out }}=T_{C H W \text {,in }}+\frac{\dot{Q}_{C H W}}{\dot{m}_{C H W} C p_{C H W}}
\end{aligned}
$$

$$
C O P=\frac{\dot{Q}_{C H W}}{\dot{Q}_{H W}}
$$

\section{Results and Discussion}

The prototypal solar heating and cooling system presented in the previous sections was simulated by using the developed TRNSYS model with the scope to analyse the variation of system energy performance as a function of the designed storage strategies. In addition, the first results of the experimental campaign are utilized in order to validate the results obtained by the simulation code.

\section{Initial Experimental Results and Model Validation}

As previously mentioned, the installation of the SHC system was completed at the beginning of the September 2014. Therefore, up to now only few weeks operating data have been collected. During this weeks, the SHC system was set in "2 Tank" (series connection of tanks) and cooling modes. Unfortunately, as expected, the maximum measured solar radiation on horizontal obtained during this period of the year is around $700 \mathrm{~W} / \mathrm{m}^{2}$, much lower than the summer peak of around $1100 \mathrm{~W} / \mathrm{m}^{2}$, achieved in July. The data collected are used to validate the model previously described. For the fixed set of models parameters (i.e., solar collectors features, ACH performance map, etc.), the simulation results of the selected model have to replicate the behavior of real system component. In fact, as common in any scientific work, the results of a numerical model can be considered as robust and reliable only when they are validated versus experimental data.

It is worth noting that simulations are performed by using weather data of Naples included in the Meteonorm database, which are not necessarily consistent with the real data of the selected day. In order to suitably perform this validation procedure, the wheatear boundary conditions for the simulation model (e.g., solar radiation and outdoor temperature) have been measured for a selected period. Then, these measured wheatear conditions have been used as input data for the simulation model. In this way, a more detailed validation procedure can be performed where the differences between measured and numerical data can be due only to an error of the model. It is also worth noting that components input parameters were previously calibrated by means of manufacturers' data. In Fig. 12 the results of this validation procedure is shown. Note that for a better comparative visualization of the results, only $4 \mathrm{~h}$ of operation are shown. During this time the $\mathrm{ACH}$ works for one hour, when $\mathrm{T}_{\text {chill, out }}$ reaches $7^{\circ} \mathrm{C}$. Conversely, when the $\mathrm{ACH}$ is deactivated, such temperature is equal to $10^{\circ} \mathrm{C}$ since the $\mathrm{ACH}$ cools the return pipe of the main HAVC system of the building. A good agreement is achieved except for a small period in which the real operating chiller was deactivated whereas the simulated one was still operating. An acceptable 
agreement is also achieved for the temperatures of the fluids within the solar collectors and the tank. Obviously, as usual in highly dynamic systems, there is no perfect matching between simulated and experimental data. As expected, measured data are more sensitive to the radiation behaviour. In addition, this graph also shows that the experimental data show a more capacitive system than those assumed in the simulations.

In fact, temperature variations in experimental measurements are much smoother than the numerical results. This difference may be due to the thermal capacity of the components implemented in the simulation model, which have been taken into account only for the tanks and the pipes. Conversely, a negligible capacity for solar collectors, absorption chiller and cooling tower, have been assumed.

\section{Simulation Model: Strategy Comparison}

The main yearly results of the simulations are summarized in Table 3. It must be noted that no auxiliary heating device is used in the investigated SHC system. Therefore, in the simulation, a solar fraction equal to 1 (all heating or cooling energy is produced by solar energy) is obtained.

The simulation is performed for $8760 \mathrm{~h}$ and a time-step of $5 \mathrm{~min}$ is used. Such small time-step is required in order to achieve convergence in capacitive components (tanks, pipes, etc.). The overall results are compliant with those available in literature for similar systems (Mateus and Oliveira, 2009; Vargas et al., 2009; Calise et al., 2010). In fact, the average solar collector efficiency is slightly higher than $30 \%$. The calculated summer average solar collector efficiency is slightly lower than the winter one. This may be an unexpected result, being solar collector

efficiency increasing as a function of the available solar radiation. However, it must be considered that such efficiency also decreases when the difference between solar collector temperature and the environmental one increases. Such temperature difference is higher during the summer, due to the higher setpoint temperature of solar collectors. This effect dominates over the higher summer solar radiation. Table 3 also shows that the average COP of the absorption chiller is very close to the nominal value. Finally, Table 3 shows that the cooling energy $\left(Q_{\text {user,sum }}\right)$ is much higher than the heating winter one $\left(\mathrm{Q}_{\text {user,wint }}\right)$. This is due to the dramatic decrease of the available radiation that occurs during the winter season, due to the very low tilt angle of the solar collectors. Finally it is also worth noting that the ratio between the cooling energy produced and the nominal capacity of the absorption chiller $(70 \mathrm{~kW})$ is very low (around $340 \mathrm{~h} /$ year), showing that, for the selected configuration, the capacity of the solar field is low compared to the heat demand of the absorption chiller.

Table 3. 1-year simulations, main results: 1 tank strategy Vs 2 tank strategy

\begin{tabular}{|c|c|c|c|}
\hline & 2 Tank & 1 Tank & Unit \\
\hline $\mathrm{I}$ & 125185 & 125185 & $\mathrm{kWh} /$ years \\
\hline $\mathrm{Q}$ coll & 40086 & 39529 & $\mathrm{kWh} /$ years \\
\hline$\eta$ coll & 32.0 & 31.6 & $\%$ \\
\hline Q coll summ & 30872 & 30379 & $\mathrm{kWh} /$ years \\
\hline$\eta$ coll summ & 31.4 & 30.9 & $\%$ \\
\hline Q coll wint & 9214 & 9150 & $\mathrm{kWh} /$ years \\
\hline$\eta$ coll wint & 34.1 & 33.9 & $\%$ \\
\hline Q hot ACH & 28760 & 29999 & $\mathrm{kWh} /$ years \\
\hline Q user, summ & 22749 & 23799 & $\mathrm{kWh} /$ years \\
\hline $\mathrm{COP} A C H$ & 0.791 & 0.793 & - \\
\hline Q user, winter & 7924 & 8466 & $\mathrm{kWh} /$ years \\
\hline
\end{tabular}

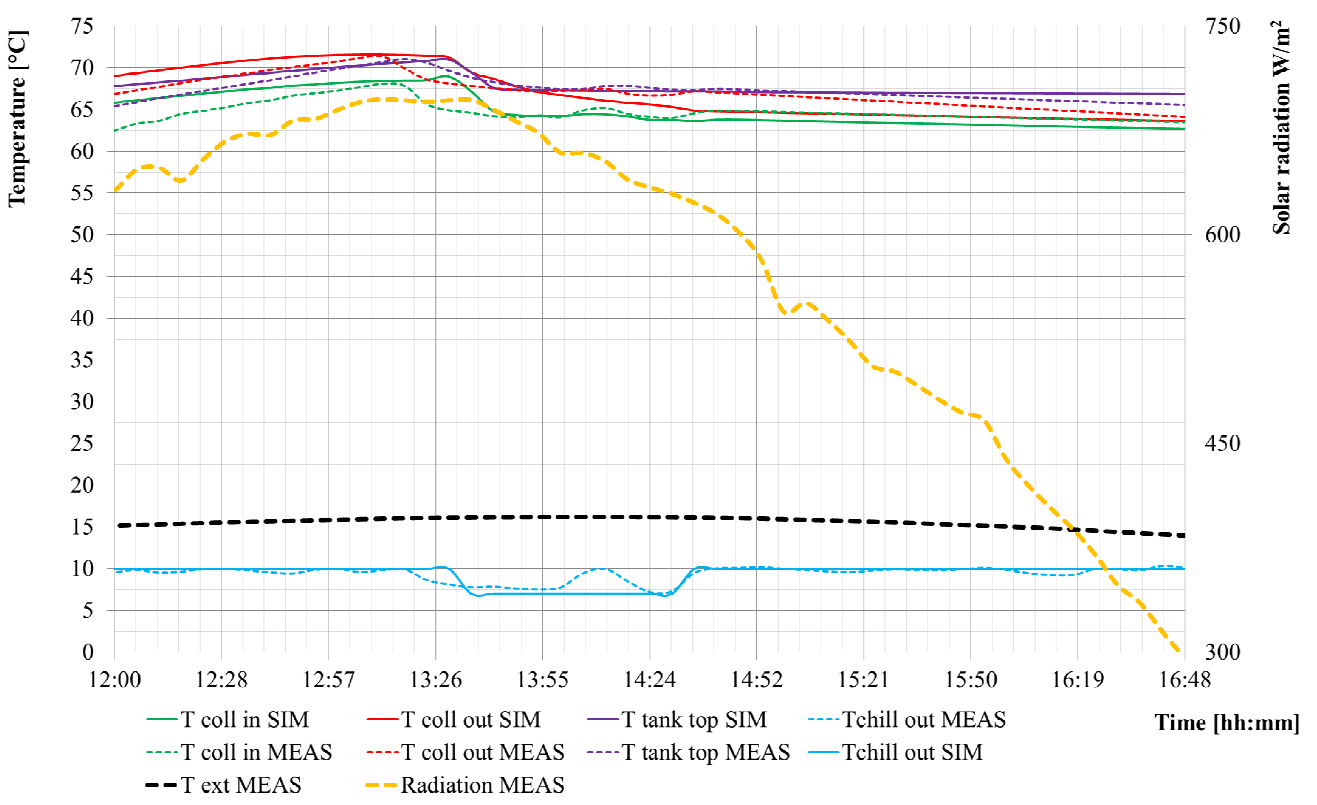

Fig. 12. Measured and simulated data comparison 
Table 3 shows also a comparison between two different storage strategies investigated in this study. These strategies are: (i) a single 15001 tank ("1 Tank" case) and ii) two 15001 tanks connected in series ("2 Tank" case). In Table 3 it is shown that the differences between the two cases are generally low. A higher amount of energy for users purpose (during both winter and summer) is obtained with the "1 Tank" strategy Vs. the "2 Tank" one. This depends on the lower capacity of the tank; in fact, in "1 Tank" configuration a higher average tank temperature is obtained due to the lower capacity. Therefore, the higher the tank temperature, the longer the time during which the tank is able to supply hot water to the absorption chiller and to the user. In case of "1 Tank" strategy a lower efficiency of the solar collectors is also obtained. In fact, in this case the average temperature of the solar collectors is higher, determining a consequent decrease of their efficiencies.

\section{Simulation Model: Daily Analysis}

A more detailed analysis of the results of the case " 1 Tank" is performed. The yearly results discussed above may be better interpreted by analysing the dynamic plots of temperatures and heat flows for a representative summer day. Figure 13 shows the inlet and outlet temperatures of the solar field and the tank.

Here, a high variability of the temperature is observed. When the temperature of the tank reaches $85^{\circ} \mathrm{C}$ the $\mathrm{ACH}$ can be activated. Then, the temperature decreases below $80^{\circ} \mathrm{C}$ and the HW circuit is stopped.

The "ON" time for $\mathrm{ACH}$ is around $20 \mathrm{~min}$, after that the tank needs $20 \mathrm{~min}$ to reach the set point temperature again. As expected, the temperature of the solar collector field is also affected by the variations in tank temperature, being the inlet solar collector temperature equal to the tank bottom one. The oscillating behaviour shown in Fig. 13 is due to the mismatch between the thermal capacity of the solar collector field and the one of the absorption chiller. This result was expected by the initial setup of the prototype plant, in which an insufficient roof area is used for the required rated capacity of the solar collector field.

This oscillating behaviour is more clearly shown in Fig. 14, where it is displayed the difference in magnitude between solar thermal power and heat demanded by the absorption chiller. In fact, the thermal power required by the $\mathrm{ACH}$ is around $70 \mathrm{~kW}$, when the solar field peak is around $30 \mathrm{~kW}$. Thus, the energy stored into the tank is useful only for $20 \mathrm{~min}$, after that other energy needs to be stored and during this time the ACH turns off. "2 Tank" strategy reduces temperature fluctuation, but thermal losses and heat capacity of the two tanks implies a decrease of the overall system performance. Obviously, the amount of energy from the solar field depends on the solar radiation (with a collectors' efficiency around $40 \%$ ).

The energy stored by the tank depends on its own temperature. When the $\mathrm{ACH}$ is activated, the power stored increases because of the tank temperature decrease; and the difference between collectors and tank temperatures increases. However, a maximum power around $35 \mathrm{~kW}$ (extremely lower than $\mathrm{ACH}$ request) is obtained. The solar field works for $11 \mathrm{~h}$ during this day, while the $\mathrm{ACH}$ works for $4.5 \mathrm{~h}$.

\section{Simulation Model: Weekly Analysis}

In order to analyse the system behaviour during all the year, a weekly analysis is performed, as shown in Fig. 15. The heating system is activated from the 1 st to the 13th week and from the 46th to the 52nd week. During the rest of the weeks, the heat supplied by the tank is utilized for cooling purpose.

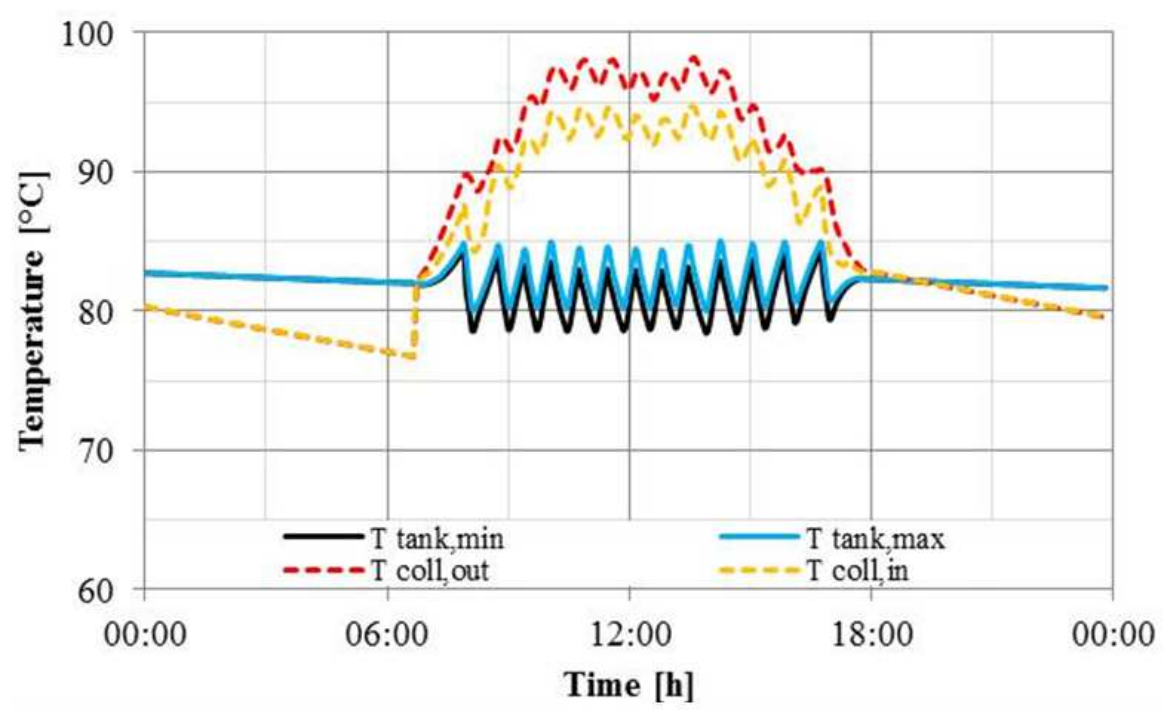

Fig. 13. Dynamic analysis: Temperature for a summer day (July 22nd) 


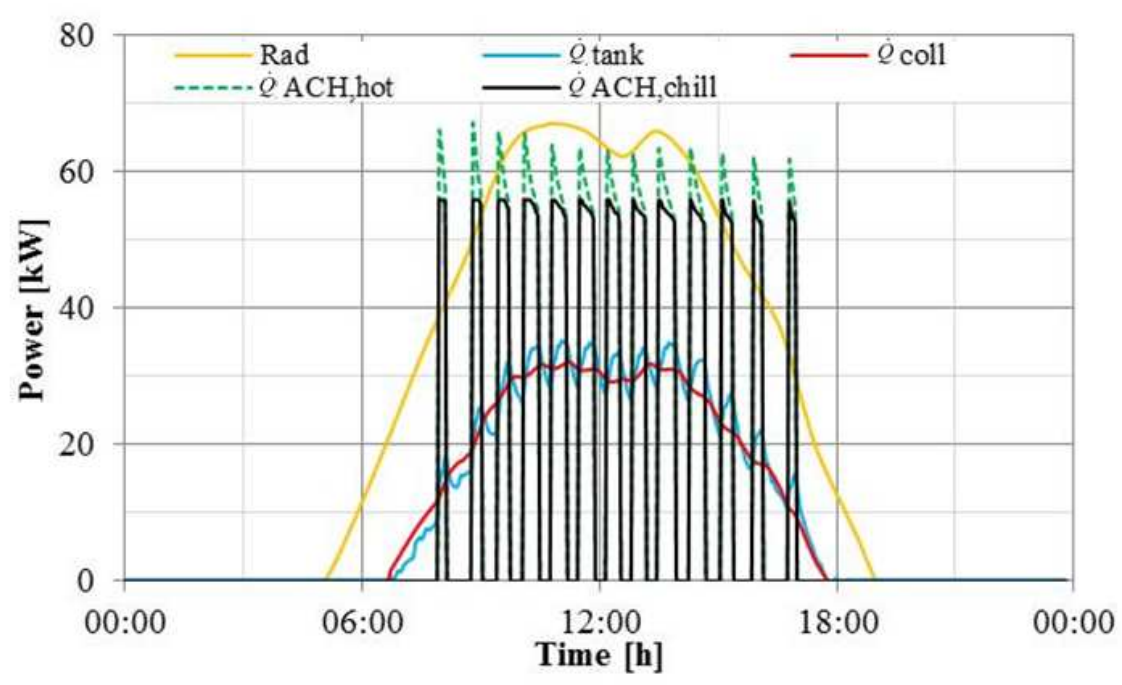

Fig. 14. Dynamic analysis: Powers for a summer day (July 22nd)

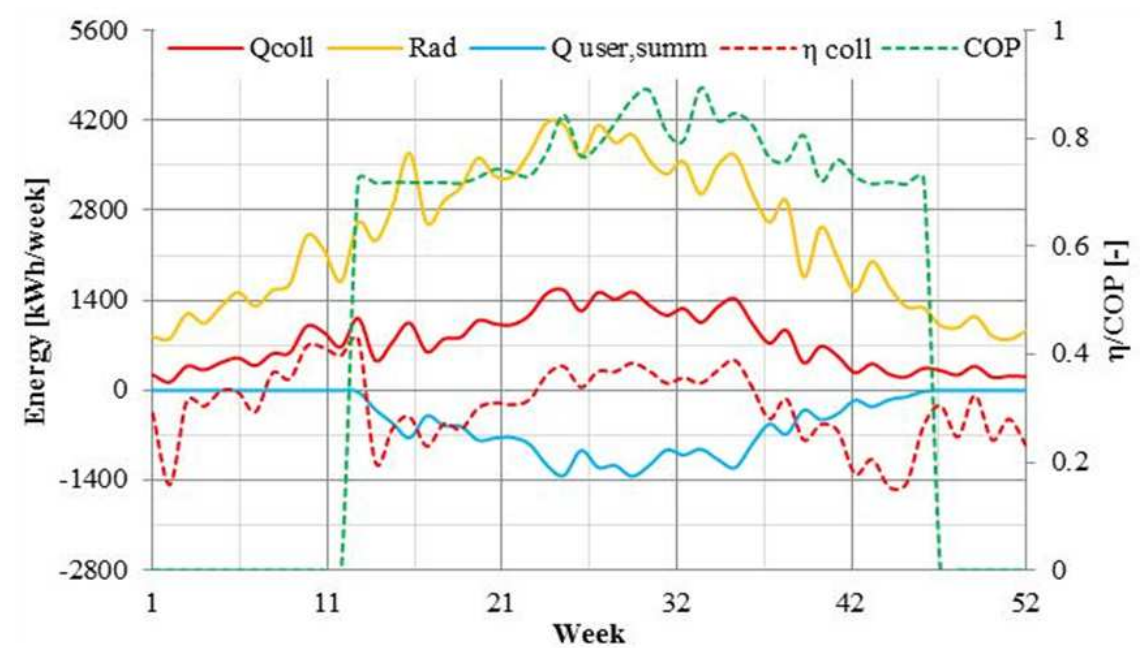

Fig. 15. Weekly analysis: Energy and performance

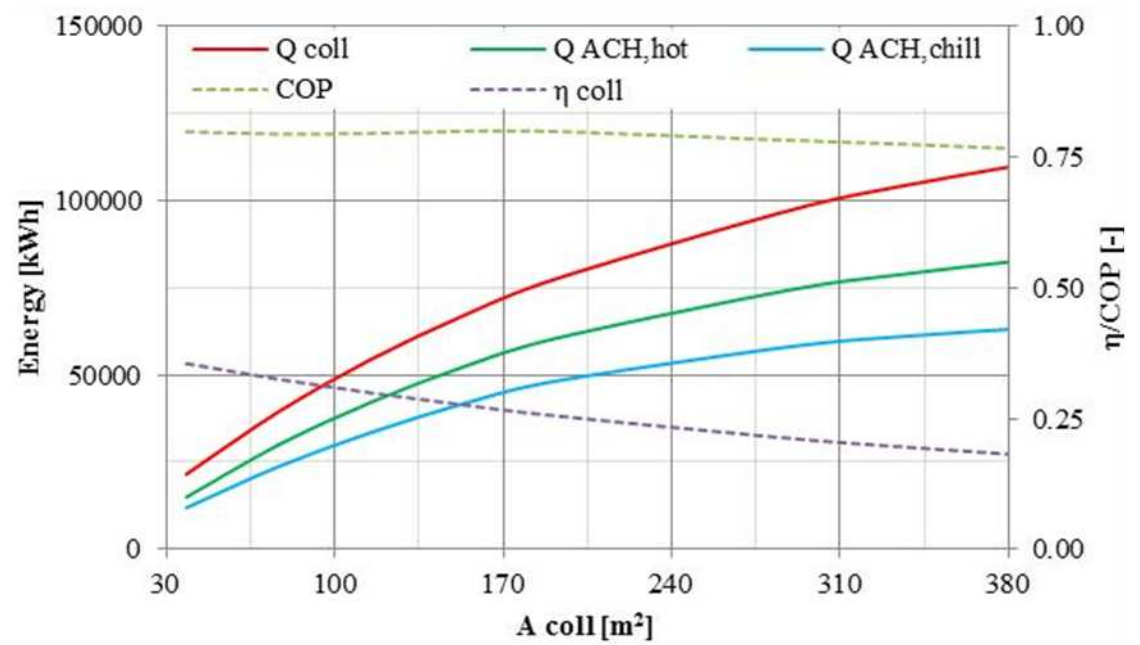

Fig. 16. Sensitivity analysis: Collectors area 


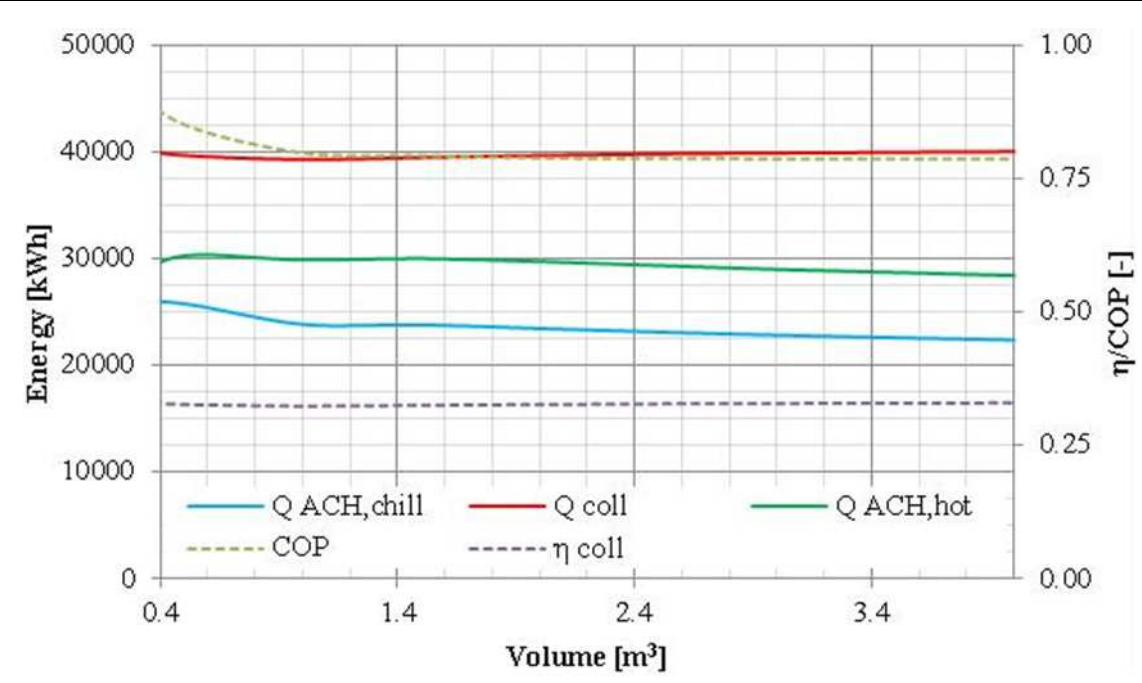

Fig. 17. Sensitivity analysis: Tank volume

Figure 15 shows a dramatic variation of the availability of solar radiation during the year. Even during the summer, weekly summer radiation may vary from about $1400 \mathrm{kWh} /$ week up to $4200 \mathrm{kWh} /$ week. As a consequence, the maximum cooling energy supplied occurs during the 25 th week, between July 1 st and 7 th and it is about $1300 \mathrm{kWh} /$ week, while during the $46 \mathrm{th}$ week, the minimum of $100 \mathrm{kWh} /$ week is reached. Similarly, thermal energy supplied during winter reaches the peak during the 10th week (from March 8to 15th). In Fig. 15 COP and the $\eta_{\text {coll }}$ are also plotted. The COP varies between 0.7 and the rated value of 0.8 , being slightly affected by the availability of solar radiation. In fact, it is well known that an increase in hot water inlet temperature determines significant variations in cooling capacity but marginal variations in absorption efficiency. The solar field has an average efficiency of $30 \%$ during all the year. In winter weeks the solar field average efficiency is around $35 \%$, while it is lower during summer (as before described in the previous paragraph and in Table 3 ). This result is justified by the higher summer operating temperature of the solar collector field.

\section{Simulation Model: Sensitivity Analysis}

A sensitivity analysis is also performed. In this study, the solar field area is varied from 38 to $380 \mathrm{~m}^{2}$. Figure 16 shows the simulation results. As expected, when collectors area increases, the supplied energy increases too. It must be noted that this behaviour is not linear since the capacity of the remaining components (tanks, chiller, cooling tower, etc.) remains fixed. The efficiency of the solar collectors decreases because of the consequent increase of their operative temperature. In fact, the larger the solar field, the higher the average temperature of the solar collectors. It is also worth noting that the COP is slightly dependent on the solar field area. In fact, an increase of the solar field area determines a general increase of the temperature of the hot water supplying the absorption chiller and an increase of the chiller part load ratio.

These two parameters marginally affect the COP of the absorption chiller. A sensitivity analysis on the storage volume is also performed, as shown in Fig. 17. The tank volume variation ranges from 0.4 to $4 \mathrm{~m}^{3}$.

It is worth noting that the variation of this parameter do not affect the system performances. In fact, $\mathrm{Q}_{\mathrm{ACH} \text {,chill }}$ and $\mathrm{Q}_{\mathrm{ACH} \text {,hot }}$ show a slight decrease due to the longer time needed to increase the water temperature until the set point for a larger tank volume.

The collectors performance is slightly affected by the tank volume. In this case, by increasing the tank volume, the average temperature decreases and $\eta$ slightly increases (from 32.7 to $33.0 \%$ ). The COP is stable with the exception of a small tank volume case. In fact, in this case the set point temperature is rapidly reached and the $\mathrm{ACH}$ works for a longer period. Hence, $\mathrm{Q}_{\mathrm{ACH} \text {,chill }}$ is higher in case of a small volume.

\section{Conclusion}

In this study a numerical and experimental analysis of a prototypal solar heating and cooling system located in Naples (Italy) is presented. The dynamic simulation model of the system behavior is developed by means of a zero-dimensional transient simulation model developed in TRNSYS. Then, this model has been successfully validated by means of the experimental data obtained since the initial operation of the prototypal system.

The analysis shows a significant mismatch between the thermal capacity of the solar field and the heat demanded by the absorption chiller. As a result, a 
discontinuous operation of the absorption chiller is achieved. This mismatch is balanced by the storage system. Such results were obtained through both numerical and experimental data. Unfortunately, a higher capacity of the solar field than the one installed was not compatible with the available roof area of the installation site. The average yearly efficiency of the solar collectors was slightly higher than $30 \%$, being higher in the winter with respect to the summer. This result is due to the higher operating temperature of the solar collector field required to drive the absorption chiller. The COP of the absorption chiller was stably around its rated value (0.80), being marginally affected by the variations of solar radiation availability and by the remaining boundary conditions. Finally, different storage strategies are analyzed. Simulation results show that a better management of the storage volume is achieved by adopting a single tank ("1 Tank" case) strategy. In this case, a higher utilization factor of the absorption chiller is obtained.

The sensitivity analysis also shows that when the solar collector field area increases, the energy collected increases too. However, the system performance decreases. In addition, by varying the tank volume, a marginal system performance variation is also obtained.

Note that, in this study the presented experimental results have been collected from the start-up of the analyzed prototypal system, occurred in September 2014. In future works, the results of a planned 1-year experimental campaign will be presented, with the aim of showing the long term performance of the investigated solar heating and cooling system.

\section{Acknowledgement}

This work has been financially supported by the Italian Ministry of Environment (Ministero dell'Ambiente e della Tutela del Territorio e del Mare)Research project "SAHARA: Solar-Assisted Heating And Refrigeration Appliances" (CUP: F61C07000070003).

\section{Funding Information}

The authors have no support or funding to report.

\section{Author's Contributions}

All authors contributed equally to this work, they also revised and approved the manuscript.

\section{Ethics}

This article is original and contains unpublished material. The corresponding author confirms that all of the other authors have read and approved the manuscript and no ethical issues involved.

\section{References}

Assilzadeh, F., S.A. Kaligirou, Y. Ali and K. Sopian, 2005. Simulation and optimization of a $\mathrm{LiBr}$ solar absorption cooling system with evacuated tube collectors. Renewable Energy, 30: 1143-1159.

DOI: $10.1016 /$ j.renene.2004.09.017

Atamaca, I. and Y. Abdulvahap, 2003. Simulation of solar-powered absorption cooling system. Renewable Energy, 28: 1277-1293. DOI: $10.1016 / \mathrm{S} 0960-1481(02) 00252-5$

Baldwin, C. and C.A. Cruickshank, 2012. A review of solar cooling technologies for residential applications in Canada. Energy Procedia, 30: 495-504. DOI: 10.1016/j.egypro.2012.11.059

Beccali, M., M. Cellura, S. Longo, B. Nocke and P. Finocchiaro, 2012. LCA of a solar heating and cooling system equipped with a small waterammonia absorption chiller. Solar Energy, 86: 1491-1503. DOI: 10.1016/j.solener.2012.02.010

Buonomano, A., F. Calise and G. Ferruzzi, 2013. Thermoeconomic analysis of storage systems for solar heating and cooling systems: A comparison between variable-volume and fixed-volume tanks. Energy, 59: 600-616.

DOI: 10.1016/j.energy.2013.06.063

Buonomano, A., F. Calise, G. Ferruzzi and L. Vanoli, 2014. Variable-volume storage systems for solar heating and cooling system: A case study for different Italian climates. Energy Procedia, 48: 290-299. DOI: 10.1016/j.egypro.2014.02.034

Calise, F., 2012. High temperature solar heating and cooling systems for different Mediterranean climates: Dynamic simulation and economic assessment. Applied Thermal Eng., 32: 108-124. DOI: 10.1016/j.applthermaleng.2011.08.037

Calise, F., G. Ferruzzi and L. Vanoli, 2012. Transient simulation of polygeneration systems based on PEM fuel cells and solar heating and cooling technologies. Energy, 41: 18-30. DOI: $10.1016 /$ j.energy.2011.05.027

Calise, F., 2010. Thermoeconomic analysis and optimization of high efficiency solar heating and cooling systems for different Italian school buildings and climates. Energy Build., 42: 992-1003. DOI: $10.1016 /$ j.enbuild.2010.01.011

Calise, F., M. Dentice d'Accadia and A. Palombo, 2010a. Transient analysis and energy optimization of solar heating and cooling systems in various configurations. Solar Energy, 84: 432-449. DOI: $10.1016 /$ j.solener.2010.01.001

Calise, F., A. Palombo and L. Vanoli, 2010b. Maximization of primary energy savings of solar heating and cooling systems by transient simulations and computer design of experiments. Applied Energy, 87: 524-540.

DOI: $10.1016 /$ j.apenergy.2009.08.033 
Calise, F., M.D. d'Accadia and L. Vanoli, 2011. Thermoeconomic optimization of solar heating and cooling systems. Energy Convers. Manage., 52: 1562-1573. DOI: 10.1016/j.enconman.2010.10.025

Ghaddar, N.K., M. Shihab and F. Bdeir, 1997. Modeling and simulation of solar absorption system performance in Beirut. Renewable Energy, 10: 539-558. DOI: 10.1016/S0960-1481(96)00039-0

Grynning, S., B. Time and Barbara Matusiak, 2014. Solar shading control strategies in cold climates Heating, cooling demand and daylight availability in office spaces. Solar Energy, 107: 182-194.

DOI: 10.1016/j.solener.2014.06.007

Hammad, M. and Y. Zurigat, 1997. Performance of a second generation solar cooling unit. Solar Energy, 62: 79-84. DOI: 10.1016/S0038-092X(97)00105-9

Hang, Y., L. Du, M. Qu and S. Peeta, 2013. Multiobjective optimization of integrated solar absorption cooling and heating systems for medium-sized office buildings. Renewable Energy, 52: 67-78. DOI: 10.1016/j.renene.2012.10.004

Hang, Y., M. Qu, R. Winston, L. Jiang and B. Widyolar et al., 2014. Experimental based energy performance analysis and life cycle assessment for solar absorption cooling system at University of Californian, Merced. Energy Build., 82: 746-757. DOI: 10.1016/j.enbuild.2014.07.078

Henning, H.M. and J. Döll, 2012. Solar systems for heating and cooling of buildings. Energy Procedia, 30: 633-653. DOI: 10.1016/j.egypro.2012.11.073

IEA, 2011. Solar cooling position paper: Task 38 Solar Air-Conditioning and Refrigeration.

Kalogirou, S.A., 2014. Chapter 6-Solar Space Heating and Cooling. In: Solar Energy Engineering: Processes and Systems, Kalogirou, S.A., Academic Press, Amsterdam, ISBN-10: 0123972566, pp: 323-395.

Klein, S.A., 2006. TRNSYS: A transient system simulation program. University of Wisconsin, Madison.

Koroneos, C. and M. Tsarouhis, 2012. Exergy analysis and life cycle assessment of solar heating and cooling systems in the building environment. J. Cleaner Product., 32: 52-60.

DOI: $10.1016 /$ j.jclepro.2012.03.012

Mateus, T. and A.C. Oliveira, 2009. Energy and economic analysis of an integrated solar absorption cooling and heating system in different building types and climates. Applied Energy, 86: 949-957. DOI: 10.1016/j.apenergy.2008.09.005

Mosallat, F., T. Elmekkawy, T. ELMekkawy, D.L. Friesen and T. Molinski et al., 2013. Modeling, simulation and control of flat panel solar collectors with thermal storage for heating and cooling applications. Procedia Comput. Sci., 19: 686-693. DOI: $10.1016 /$ j.procs.2013.06.091
Nowag, J., F. Boudéhenn, A. Le Denn, F. Lucas and O. Marc et al., 2012. Calculation of performance indicators for solar cooling, heating and domestic hot water systems. Energy Procedia, 30: 937-946. DOI: $10.1016 /$ j.egypro.2012.11.106

Vargas, J.V.C., J.C. Ordonez, E. Dilay and J.A.R. Parise, 2009. Modeling, simulation and optimization of a solar collector driven water heating and absorption cooling plant. Solar Energy, 83: 1232-1244. DOI: 10.1016/j.solener.2009.02.004

Wang, Y., Y. Cui, L. Zhu and L. Han, 2008. Experiments on novel solar heating and cooling system. Energy Convers. Manage., 49: 2083-2089. DOI: 10.1016/j.enconman.2008.02.024

Yu, Z., J. Ji, W. Sun, W. Wang and G. Li et al., 2014. Experiment and prediction of hybrid solar air heating system applied on a solar demonstration building. Energy Build., 78: 59-65.

DOI: $10.1016 /$ j.enbuild.2014.04.003

\section{Nomenclature}

$a_{0} \quad$ Intercept (maximum) of the collector efficiency [-]

$a_{1} \quad$ Negative of the first-order coefficient in collector efficiency equation $\left[\mathrm{kJ} / \mathrm{hm}^{2} \mathrm{~K}\right]$

$a_{2} \quad$ Negative of the second-order coefficient in collector efficiency equation $\left[\mathrm{kJ} / \mathrm{hm}^{2} \mathrm{~K}^{2}\right]$

$c_{p} \quad$ Specific heat $[\mathrm{J} / \mathrm{kgK}]$

$F_{R} \quad$ Overall collector heat removal efficiency factor

$h$ hour [h]

I Global solar irradiance $\left[\mathrm{kW} / \mathrm{m}^{2}\right]$

$\dot{m}$ Mass flow rate $[\mathrm{kg} / \mathrm{s}]$

$\dot{Q} \quad$ Thermal power $[\mathrm{kW}]$

$Q \quad$ Heat $[\mathrm{kWh}]$

$S \quad$ Surface area $\left[\mathrm{m}^{2}\right]$

$T \quad$ Temperature $\left[{ }^{\circ} \mathrm{C}\right]$

$U A$ Thermal transmittance $[\mathrm{kJ} / \mathrm{hK}]$

$U_{L} \quad$ Overall thermal loss coefficient of the collector per unit area $\left[\mathrm{kJ} / \mathrm{hm}^{2} \mathrm{~K}\right]$

$U_{L / T}$ Thermal loss coefficient dependency on the temperature $\left[\mathrm{kJ} / \mathrm{hm}^{2} \mathrm{~K}\right]$

$\mathrm{V} \quad$ Volume $\left[\mathrm{m}^{3}\right]$

$\eta \quad$ Efficiency [-]

\section{Abbreviations}

$\begin{array}{ll}\text { ACH } & \text { Absorption Chiller } \\ \text { CHW } & \text { Chilled Water } \\ \text { COP } & \text { Coefficient of Performance } \\ \text { DHW } & \text { Domestic Hot Water } \\ \text { FPC } & \text { Flat Plate Thermal solar collectors } \\ \text { CT } & \text { Cooling Tower } \\ \text { CW } & \text { Cooling Water Loop } \\ \text { HE } & \text { Heat Exchanger } \\ \text { HF } & \text { Hot Fluid } \\ \text { P } & \text { Pump }\end{array}$


SC Solar Collector field

SCF Solar Collector Fluid

SHC Solar Heating and Cooling

\section{Subscripts}

a Referred to outside air dry bulb

$A C H \quad$ Referred to absorption chiller

$\mathrm{CHW}$ Referred to chilled water

coll Referred to solar collectors

cool Cooling

$C W \quad$ Referred to the cooling water stream fluid

$f \quad$ Referred to fluid

heat Heating

$H W \quad$ Referred to the hot water stream fluid

$i \quad$ Referred to the i-th tank segment

in Inlet

$L \quad$ referred to the fluid going to the load

$\max \quad$ Maximum

MEAS Referred to measured data

min Minimum

out Outlet

$p \quad$ Referred to pump

rated Referred to nominal capacity

req Required

SIM Referred to simulated data

summ Referred to summer season

$T \quad$ Referred to global

tank Referred to tank

th Referred to thermal energy

TOT Total

TOW Referred to cooling tower

tank Referred to tank

user Referred to the users

winter Referred to winter season 